Original Research Article

\title{
Cognitive Engagement Games on Academic Performance in Mathematics of Pupils with Hearing Impairment in Imo State
}

\author{
Nwachukwu Kingsley Ezechinyere $(\mathrm{PhD})^{1^{*}}$, Okoro, Uloaku Nene $(\mathrm{PhD})^{2}$, Anyanwu Chikodi Joy $(\mathrm{PhD})^{3}$ \\ ${ }^{\mathrm{T}}$ Department of earlychildhood and Special Education, Faculty of Education, University of Uyo \\ ${ }^{2,3}$ Department of Special Needs Education, Alvan Ikoku Federal Collage of Education, Owerri
}

*Corresponding Author

Nwachukwu Kingsley Ezechinyere

\section{Article History}

Received: 21.01.2021

Accepted: 09.02.2021

Published: 19.02.2021

\begin{abstract}
The study investigated effect of cognitive engagement games on academic performance of pupils with hearing impairment in mathematics in primary schools in Imo State. Quasi experiment of nonrandomized pretest posttest design was adopted for the study. Three research objectives, and hypotheses were formulated which guided the study. The research utilized two experimental groups; cognitive engagement card game and cognitive engagement macula board-seed game, a control group while the sample size was 104 pupils with hearing impairment from three intact classes. The two experiment groups were engaged in mathematical games; cognitive engagement card and cognitive engagement macula board-seed game while the control group was taught with the use of convention method. The instrument titled Mathematics Operation and Application Performance Test MOAPT with a total of 20 questions, 5 questions from each of the four topics of the lesson was used. ANCOVA statistics was used in testing the research hypotheses at 0.05 level of significance. The results revealed that pupils engaged in both cognitive engagement card and cognitive engagement macula board-seed games had higher performance scores than the control group. The game methods were found to be the most effective in improving pupils' performance in mathematics.
\end{abstract}

Keywords: Cognitive Engagement Games, Academic Performance, Hearing Impairment.

\section{INTRODUCTION}

Over the years, instructional strategies on academic performance attracted the attention of researcher. Okigbo [1] carried out a study on effectiveness of mathematical game and instructional analogy as advance organizer on students' interest in mathematics in Awka, Anambra state, noted that the use of instructional games promotes students interest. In the same vein Unamba, Nwaneri and Nwabo [2], investigated the effect of game and poem enhanced instruction on pupil's achievement in mathematics in Owerri Municipal and Owerri North local government areas. The result revealed that pupils' high achievement in mathematics with game than poem.

In a more recent study by Ogbonna [3], on Gaming instructional strategy and achievement of preschoolers in number work in Abia South noted a significant difference in preschoolers' achievement scores in number work using instructional gaming and conventional method. Based on the researcher's 8 years of personal experience as a teacher, the researcher holds the conviction that instructional strategy makes or mars pupils' performance in mathematics. Some researchers focused more on gaming and achievement, games and poem in teaching mathematics, gaming and interest in mathematics to the neglect of using cognitive engagement card game and cognitive engagement macula board seed games based method on pupils with hearing impairment performance in mathematics. No such researches have been carried out with person with hearing impairment. It is against such background that spelt the rationale for this study.

Children with hearing impairment may have partial or full hearing loss on one or both ears Hardman, Drew and Egan [4]. The characteristics exhibited by students depend on the degree of hearing loss and the onset of that loss. According to Chimedza and Peterson [5] the earlier the hearing loss manifest itself in a child the more difficult he or she will have in developing the spoken language. A hearing handicap or deafness involves not only the loss or impairment of

Copyright @ 2021 The Author(s): This is an open-access article distributed under the terms of the Creative Commons Attribution 4.0 International License (CC BY-NC 4.0) which permits unrestricted use, distribution, and reproduction in any medium for noncommercial use provided the original author and source are credited. 
hearing, but the loss or limitation of the ability to acquire language and speech naturally or spontaneously [6]. Impaired or total lack of language has serious implications for the child's development. It is worth nothing that the characteristics of a child with mild hearing loss are in many ways more similar to a hearing child's than to a deaf child's characteristic. It causes a number of other serious problems that are linked to the inability to receive or express message and thoughts [7].

The poor performance of learners with hearing impairment in mathematics across primary and secondary schools in Nigeria is a problem in educational system because a faulty foundation is hazardous. However, game is an excellent activity for proper development and growth of children in all aspects of life including the hearing impaired. Game helps in developing children's intellectual ability for learning. The notion that children learn through play began with Frobel. He believed that unfolding development occurs through play. The word game is synonym to play. Consequently, in this study, game and play are used interchangeably. Experimental research on motivation and learning suggest that pupils have more interest on cognitive engagement game based learning (Barrak \& Raz, 2000 cited in Ekanenem, 2012[8]).

Cognitive engagement games are educational sports activities used in the learning process to acquire and impact the skill of comprehension, reasoning, reproduce form memory, retain information do operation and application by the learner. Tom Dewing [9], states that "cognitive engagement game based learning is the technique of teaching and learning where are engaged, actively participate and pursue knowledge they are preparing for in the learning process". Dewing [9] quoted Kidwell [10] "Pupils engagement in active learning which facilitates classroom discussions".

\section{Statement of the Problem}

Pupils with hearing impairment have poor performance in operation and application of basic mathematics concepts and skills respectively. Poor performance in mathematics operation and application leads to poor application and performance in science and technology, this is because mathematics is a core subject and central point to different disciplines especially sciences and technology. Poor performance of these learners generally in mathematics may bring about poor performance in sciences and technology at the higher levels of education

The different instructional methods used by teachers to teach pupils with hearing impairment at different stages considering the learners' age and lesson content. The researcher observed that teachers of pupils with hearing impairment in Imo State are reluctant to the clarion call of a shift to the use of engagement in game-play method which is active based learning method of instruction. The researcher therefore postulates that there is need to search for ways and games for use to ameliorate this problem and to see if the use of cognitive engagement games will help out. This study sought to examine the effect of two cognitive engagement games strategies; cognitive engagement card game, cognitive engagement macula board- seed game, and conventional method on academic performance of pupils with hearing impairment in mathematics. Hence the question addressed in the study is, does cognitive engagement games strategy improves pupils with hearing impairment performance in operation and application of mathematics?

\section{Purpose of the Study}

The purpose of this study is to find out the effect of cognitive engagement games on pupils with hearing impairment performance in mathematics specifically, the study

- Determine the difference between Mathematics performance of pupils with hearing impairment expose to cognitive engagement card games strategy and those taught with conventional method of instruction.

- Ascertain the difference between mathematics performances of pupils with hearing impairment exposed to cognitive engagement Macula Board-seed game and those taught using conventional method of instruction.

- Examine the difference between mathematics performance of pupils with hearing impairment exposed to cognitive engagement card game and those exposed to Macula Board-seed game.

\section{Research Hypothesis}

1. There is no significant difference in the mathematics performance scores of pupils with hearing impairment exposed to cognitive engagement card game and those taught using conventional method of instruction.

2. There is no significant difference between the mathematics performance scores of pupils with hearing impairment exposed to cognitive engagement macula board-seed game and those taught with conventional method.

3. The mathematics performance scores of pupils with hearing impairment exposed to cognitive engagement card games and cognitive engagement macula board-seed game does not differ significantly. 


\section{RESEARCH DESIGN}

The Quasi experimental design of non-randomised pretest - posttest control group was used for this study because it involved classroom experiment where experimental and control groups were intact classes.

The structural representation of non-randomised pretest - posttest control group design used in this study is represented as follows:

$\begin{array}{llll}\mathrm{O}_{1} & \mathrm{X}_{1} & \mathrm{O}_{2} & \left(\mathrm{E}_{1}\right) \\ \mathrm{O}_{3} & \mathrm{X}_{2} & \mathrm{O}_{4} & \left(\mathrm{E}_{2}\right) \\ \mathrm{O}_{5} & \mathrm{X} 3 & \mathrm{O}_{6} & (\mathrm{C})\end{array}$

Where

$\mathrm{O}_{1}=$ Pretest scores of first experimental condition.

$\mathrm{O} 3=$ Pre test scores of second experimental condition.

$\mathrm{O} 5=$ Pre test scores of the control group

$\mathrm{O} 2=$ Post test scores of the first experimental condition

$\mathrm{O} 4=$ Post test score of the second experimental condition.

O6 $=$ Post test scores of the control group.

$\mathrm{X}_{1}, \mathrm{X}_{2}=$ Experimental treatment or condition.

$\mathrm{X} 3=$ Control condition

$\mathrm{C}=$ Control group.

$\mathrm{E}_{1}=$ Experimental group one

$\mathrm{E} 2=$ Experimental group two

With regards to the above, individual group design can be obtained as follows:

\begin{tabular}{|c|c|c|}
\hline Group $1: \mathrm{O}_{1}$ & $\mathrm{X}_{1}$ & $\mathrm{O}_{2}$ \\
\hline Group 2: $\mathrm{O}_{3}$ & $\mathrm{X}_{2}$ & $\mathrm{O}_{4}$ \\
\hline Group $3: \mathrm{O}_{5}$ & x3 & $0_{6}$ \\
\hline
\end{tabular}

\section{Area of the Study}

The study was carried out in Imo State (the eastern heartland). Owerri is the capital of Imo State and is made up of three zones. Lying in latitude 5.29'1.07' North, longitude 7'01' "59.70" East. Elevation above sea level = 73 metres = 239ft. is bounded at the East by Anamabra State, on the South by Ebonyi State, Enugu State and some parts of Abia State, and on the south by Rivers State.

\section{Population of the Study}

The population of the study comprises all the 120 primary one schools pupils with hearing impairment in the public primary Special Schools in Imo State (IMSUBEB, 2019/2020). The study concentrated on primary one and their course content (module). The choice of primary one class is because it is a foundation laying class where all the basic rules, procedures are laid.

\section{Sample and Sampling Technique}

The sample size of the study was 104 primary one pupils with hearing impairment from the special primary schools. Three intact primary one classes were selected from the three schools through simple random sampling technique by balloting.

\section{Instrumentation}

The instrument for data collection was a test instrument titled Mathematics Operation and Application Performance Test (MOAPT) developed by the researcher. The MOAPT instrument contains a total of 20 questions, 5 questions from each of the 4 topics on addition, subtraction, open sentence and basic shape.

\section{Validation of the Instrument}

The face and content validation of the instrument was established through the process of expert review. The test items were given to two lecturers in Earlychildhood and Special Education and an expert in test and measurement all of University of Uyo. The comments, suggestions and inputs of these experts were in co-operated into the final draft of the instrument.

\section{Reliability of the Instrument}

The reliability of the instrument was determined through the test retest method. The instrument was trial tested in Abia State. Simple random sampling was used to draw a sample of 20 primary one pupils with hearing impairment. Copies of the instrument were administered to the sample. After an interval of two weeks, the same instrument in posttest 
form was administered to the same sample after treatment. The initial and the retest scores of the sample were correlated using Pearson Product moment correlation (PPMC). The reliability co-efficient of the entire instrument was determined and found to be 0.78 . This coefficient value is high enough to permit the use of the instrument for the study.

\section{MeThod OF DATA COLLECTION}

Mathematics operation and application performance test (MOAPT) was administered to the experimental and control groups respectively as pretest and posttest. After treatment the pretest and post test scores are compared to determine the difference in mathematics operation and application performance scores when exposed to cognitive engagement card game, cognitive engagement macula board game, and conventional method.

\section{MeTHOD OF DATA ANALYSIS}

The data Collected was analysed using Analysis of Covariance (ANCOVA) in testing the hypothesis at 0.05 level of significance.

\section{RESULTS \\ Hypothesis One}

There is no significant difference between the mathematics performance scores of pupils with hearing impairment exposed to cognitive exposed card game and those taught with conventional method of instruction.

Table-1: Summary of ANCOVA of mathematics performance scores of pupils with hearing impairment exposed to cognitive engagement card game and those taught with conventional method of instruction

\begin{tabular}{|l|l|l|l|l|l|l|}
\hline Sources Variation & SS & df & MS & F.cal & F.crit & Decision \\
\hline Corrected model & 1979.86 & 2 & 989.933 & 4,426 & & \\
\hline Intercept & 5295.111 & 1 & 5295.11 & 23.68 & & \\
\hline Pre-test (Covariate) & 563.765 & 1 & 563.766 & 2.521 & & \\
\hline Treatment & 1897.53 & 1 & 1897.53 & 8.484 & 3.25 & Reject Ho \\
\hline Error & 8275.23 & 37 & 223.655 & & & \\
\hline Total & 169772.0 & 40 & & & & \\
\hline Corrected Total & 10255.10 & 39 & & & \\
\hline
\end{tabular}

Data analysis in Table 1 indicates computed F-value (8.48) than the critical F value (3.25).This result led to the rejection of the null hypothesis under $\mathrm{df}=1: 39$ and at $\mathrm{P}<.05$ which revealed that there is a significant difference in the mathematics performance scores of pupils with hearing impairment exposed to cognitive card game and conventional method of instruction.

\section{Hypothesis Two}

There is no significant difference between the mathematics performance scores of pupils with hearing impairment exposed to cognitive engagement macula board-seed game strategy and those taught with conventional method.

Table 2: Summary of ANCOVA of mathematics performance scores of pupils with hearing impairment exposed to cognitive engagement macula board-seed game and conventional method of instruction

\begin{tabular}{|c|c|c|c|c|c|c|}
\hline Sources Variation & SS & df & MS & F.cal & F.crit & Decision \\
\hline Corrected model & 7221.819 & 2 & 3610.91 & 20.56 & & \\
\hline Intercept & 1.165 & 1 & 1.165 & .007 & & \\
\hline Pre-test (Covariate) & 345.037 & 1 & 345.037 & 1.981 & & Reject Ho \\
\hline Treatment & 67.080 & 1 & 67.080 & 6.382 & 3.25 & \\
\hline Error & 5094.400 & 29 & 175.669 & & & \\
\hline Total & 63117.00 & 32 & & & & \\
\hline Corrected Total & 12316.219 & 31 & & & & \\
\hline
\end{tabular}

The result of data analysis in Table 2 shows a computed $F$ value (6.382) than the critical $F$ value (3.25). This result led to the rejecting of the null hypothesis under $\mathrm{df}=1: 39$ and at $\mathrm{P}<.05$ which revealed that there is a significant difference in the mathematics performance scores of pupils with hearing impairment exposed to cognitive engagement macula board-seed game strategy and those taught with conventional method. 


\section{Hypothesis Three}

There no significant difference between the mathematics performances of scores of pupils with hearing impairment expose to cognitive Engagement Card Games and Macula Board-Seed Game.

Table-3: Summary of ANCOVA of mathematics performance scores of pupils with hearing impairment exposed to cognitive engagement card games and macula board-seed game

\begin{tabular}{|c|c|c|c|c|c|c|}
\hline Sources Variation & SS & df & MS & F.cal & F.crit & Decision \\
\hline Corrected model & 882.071 & 2 & 441.035 & 4,133 & & \\
\hline Intercept & 6522.942 & 1 & 6522.942 & 61.121 & & \\
\hline Pre-test (Covariate) & 517.982 & 1 & 517.982 & 4.854 & & \\
\hline Treatment & 178.651 & 1 & 178.651 & 1.674 & 3.25 & Accept Ho \\
\hline Error & 3521.818 & 33 & 106.722 & & & \\
\hline Total & 190740.0 & 36 & & & & \\
\hline Corrected Total & 4403.889 & 35 & & & & \\
\hline
\end{tabular}

Data analysis in Table 3 shows a lower computed F-value of (1.67) than the critical F-value (3.25). This result led to the retention of the null hypothesis under $\mathrm{df}=1: 35$ and at $\mathrm{P}<.05$ which revealed that the Mathematics performance of pupils with hearing impairment taught using Cognitive Engagement Card Games and those taught using Macula Board-Seed Game do not differ significantly.

\section{The finding of the study indicates that;}

1. There is significant difference between the mathematics performance of pupils with hearing impairment exposed to card game and conventional method. Pupils with hearing impairment exposed to card game method gain more than those Taught to conventional method in mathematics.

2. There is a significant difference between mathematics performance of pupils with hearing impairment exposed cognitive engagement Macula board-seed game method and those taught with conventional method. Result show that pupils with hearing impairment exposed to cognitive engagement Macula board-seed game gain more and performed better in mathematics than those taught to conventional method.

3. There is no significant difference between mathematics performances of pupils with hearing impairment exposed to cognitive engagement card game and those exposed to cognitive engagement Macula board-seed game.

\section{CONCLUSION}

From the findings of the study, it is concluded that cognitive engagement game methods were found to be better in enhancing pupils' with hearing impairment performance in mathematics than the conventional method. Cognitive engagement instructional strategies were found to be better with pupils with hearing impairment in learning of addition, subtraction, open sentence and shapes. There was a significant difference in pupils' with hearing impairment performance in mathematics when cognitive engagement card game and conventional methods of instructions are used.

\section{RECOMMENDATIONS}

1. Teachers should use cognitive engagement gaming instructional strategies to engage pupils with hearing impairment in mathematics operation and applications as a way of socialization and academic improvement.

2. A hybrid combination of cognitive engagement card game and cognitive engagement Macula board-seed game method should be implored by primary school teachers to teach mathematics to enhance their cognitive and psychological development.

3. Curriculum planners should incorporate mathematics games into the curriculum of teacher training programmes.

4. Time table planners should incorporate games (Para soccer) into school time table for pre-primary and primary school pupils with hearing impairment for educational enhancement.

\section{REFERENCES}

1. Okigbo, E.S. (2010). Effects of games and analogies on student interests in mathematics. Unpublished PhD thesis Nnamdi Azikiwe Univerity awka Nigeria.

2. Unamba, E.C.C., Nwaneri, O., \& Nwebo, I.G (2015). Effect of games and poem enhanced instruction on pupil's advancement in mathematics. Journal of Research and Practice in Childhood Education, 1(1) 105-117.

3. Ogbonna, C.C. (2016). Games instruction strategy and achievement of pre scholars in number work in Abia North Senatorial district of Abia State. Unpublished Masters Dissertation University of Uyo. 
4. Hardman, M. L., Drew, C. J., Egan, M. W., \& Wolf, B. (2005). Human exceptionality. Boston: Allyn \& Bacon, (3, 67-78). New York.

5. Chimedza, R. M., \& Peterson, N.K. (2003). Educational Considerations for Students with Hearing Impaired pupils, SPED 201 ZOU, Harare.

6. Kapp, J. A. (1991). Children with problems: An orthopedagogical perspective. Pretoria: Ivan Schank Marschark N,(1993). Removing the barriers in deaf education. Australian Journal of Education of The Deaf, 12(2), 23-19.

7. Adoyo, P.O. (2008). Educating Deaf Children in an Inclusive setting in Kenya: Challenges Kenya.

8. Ekenem, A.G. (2012).Teaching science, technology and mathematics in earlychildhood education. In Q.I.Obinaju (Ed). Early childcare and education for university and collages of education. Uyo soulmate Press and Publishing Comp. Ltd

9. Dewing, T. (2013). Engagement the sweet spot to learn instructional strategies, motivation and engagement of students in deeper learning. Available thomasdewing@gmail.com

10. Kidwell, G. (2010). Readable computer documentation. A Journal of Computer Games. 24(3), 148-168.

\section{APPENDIX \\ MATHEMATICS OPERATIONAL AND APPLICATION PERFORMANCE TEST (MOAPT)}

Name of School:

Name of School:

Pupils ID:

Gender:

Class:

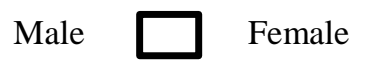

Primary One

Instruction: Choose the correct options lettered A-D. Answer all questions. All questions carry equal marks.

Match the following shapes with the correct name

1.

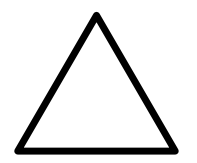

2 .

3.

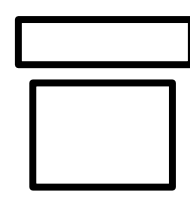

4.

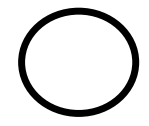

5.

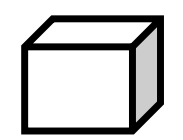

Square

Cube

Rectangle

Triangle

Circle

Subtract the following
6. $6-3=$
7. $24-8=$
8. $15-9=$
9. $19-7=$
10. $20-11=$
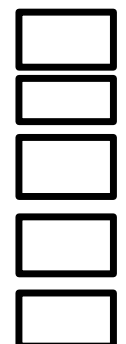

(a) 3

(b) 8

(c) 2

(d) 5

(a) 14

(b) 16

(c) 13

(d) 20

(a) 6

(b) 4

(c) 8

(d) 7

(a) 22

(b) 39

(c) 15

(d) 12

(a) 9

(b) 14

(c) 13

(d) 10 


\section{Open Sentence}

Find the missing number
11. $7+$
$=9$
(a) 3
(b) 1
(c) 2
(d) 5
12. $10-$
$=3$
(a) 7
(c) 8
(d) 5
13
$=12$
(a) 20
(b) 10
(c) 4
(d) 8
14.
$=15$
(a) 8 (b) 7
(c) 6
(d) 4
15. 7-
$=12$
(a) 20
(b) 10
(c) 4
(d) 8

Adding the following
16. $10+5=$

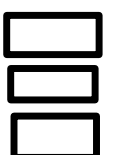
$\begin{array}{lll}\text { (a) } 8 & \text { (b) } 2 & \text { (c) } 3(d) 15\end{array}$
17. $4+5=$
$\begin{array}{lll}\text { (a) } 9 & \text { (b) } 7 & \text { (c) } 8(d) 12\end{array}$
18. $26+13=$
$\begin{array}{llll}\text { (a) } 39 & \text { (b) } 26 & \text { (c) } 12 & \text { (d) } 15\end{array}$
19. $10+26=$
(a) 30 (b) 5
(c) 36
(d) 21
20. $20+10=$
(a) 10
(b) 8 (c) 12
(d) 30

CITATION: Nwachukwu Kingsley Ezechinyere et al (2021). Cognitive Engagement Games on Academic Performance in Mathematics of Pupils with Hearing Impairment in Imo State. South Asian Res J Human Soc Sci, 3(1): 25-31. 